\title{
'HOMENS TRANS': NOVOS MATIZES NA AQUARELA DAS MASCULINIDADES?
}

\author{
Guilherme Almeida \\ Universidade do Estado do Rio de Janeiro
}

\begin{abstract}
Resumo: O artigo discute de forma exploratória a emergência de uma nova categoria identitária no Brasil, a de 'homem trans'. Essa se constrói diferenciando-se da identidade lésbica e, também, de expressões de gênero de outros grupos que tiveram seus corpos assignados como femininos ao nascimento, mas que contestam essa assignação sem, contudo, se afirmarem 'homens' de forma constante. Afirma-se que a emergência dos 'homens trans' tem sido potencializada pelo estabelecimento do processo transexualizador no SUS. Discutem-se o uso do termo "homem trans" e algumas características comuns a tais sujeitos. Problematizam-se a complexidade de seus processos de autorreconhecimento e construção de masculinidades, sua rápida capacidade de indiferenciação a partir de modificações corporais e, alguns dos efeitos políticos e subjetivos, da visibilidade e da indiferenciação.

Palavras-chave: transexualidade; homens transexuais; reconhecimento; gênero.
\end{abstract}

"De tudo ficou um pouco Do meu medo. Do teu asco. Dos gritos gagos. Da rosa ficou um pouco."

Carlos Drummond de ANDRADE, 1945.

\section{Apresentação}

Elegi discutir o que percebi como recorrente em meio à diversidade do microcosmo de 'homens trans' a que tenho tido acesso, também ele marcado por dissidências e conformações, como sugere o título deste dossiê.

Para efeito deste artigo, considero como equivalentes as categorias empíricas "homem transexual", "homem trans", "transhomem", "transman", "FTM"l ou "transexual masculino". Dessa forma, para evitar o uso de múltiplas expressões, utilizarei o termo "homem trans" no esforço de condensar a experiência da 'transexualidade masculina'. Tomo a autodenominação a partir das categorias acima, como critério de nomeação.

Copyright (๑) 2012 by Revista Estudos Feministas.

'Sigla em inglês utilizada pelos próprios transexuais e também na literatura médica para designar o que tenho chamado de 'homem trans'. Literalmente significa female-to-male, feminino para masculino'. 
Os que se identificam como 'homens trans' são ainda poucos no Brasil, e essa primeira constatação associa-se à escassez de estudos, também descrita por Ávila e Grossi: ${ }^{2}$

são praticamente inexistentes no Brasil, estudos sobre transmasculinidade e que os transexuais masculinos, parecem ter menos visibilidade que as transexuais femininas, tendo em vista a ampla variedade de estudos sobre travestilidades femininas como os de Marcos Benedetti (2005), Don Kulick (1996, 1997, 1998), Roger Lancaster (1998) e Fernanda de Albuquerque e Maurizio Janelli (1995), e transexualidade feminina, como o estudo de Berenice Bento (2006) em comparação com a quase inexistência de similares sobre transexualidade masculina.

Conheci apenas 12 'homens trans' através de colisões numa instituição de saúde que compõem o processo transexualizador no SUS, ${ }^{3}$ através de e-mails e em alguns fóruns políticos/acadêmicos. É a partir desse acesso ao empírico que escrevo.

Meu ponto de partida é o de alguém que, próximo de diferentes 'experiências trans', deseja submetê-las à crítica, condição necessária para que a produção de conhecimento cresça. A reflexão é fundamental para elaborar politicamente o enfrentamento das violações aos direitos humanos que acompanham as trajetórias dos que transcendem os limites do binarismo fundado no processo de assignação sexual pela aparência dos órgãos genitais que acompanha (e, algumas vezes, precede) o nascimento. É o caso de intersexuais e, sem dúvida, de transexuais.

Entendo que os elementos de minha experiência particular necessariamente se associam aos de outras pessoas que vivenciam a transexualidade - mulheres e homens , já que aqui o ponto de vista provém de tradições teórico-metodológicas ${ }^{4}$ que compreendem as histórias individuais não como manifestações psicológicas autônomas, mas como expressões de processos sociais e culturais amplos que informam as características dos indivíduos e são simultaneamente transformados por eles. Falo de associação, e não de replicação, entretanto.

Nesse sentido, convém resgatar o uso que Regina Facchini ${ }^{5}$ dá ao conceito de interseccionalidade: "pela idéia de 'diferença' como categoria analítica, tomando diferença de modo não essencial, mas como categoria que remete à designação de 'outros'". Para a autora, trata-se da necessidade de evitar o reducionismo de fazer derivar todas as diferenças de uma única instância determinante, desconsiderando-se a articulação de marcadores sociais de diferença (sempre existente nas trajetórias de indivíduos e grupos), como a classe social, a geração, a trajetória sexual e reprodutiva e os atributos de gênero.

Também Laura Moutinho ${ }^{6}$ destaca a necessária perspectiva interseccional, ao realizar qualquer análise dos marcadores sociais da diferença, acrescentando outros, além dos enunciados por Facchini, como a existência de deficiências físicas e as de habitação/

${ }^{2}$ Simone ÁVILA e Miriam Pillar GROSSI, 2010, p. 1

${ }^{3}$ O processo transexualizador no SUS foi instituído pela Portaria n. 1.707, do MS, de 18 de agosto de 2008. A maior parte das cirurgias dos 'homens trans' foram retiradas do caráter experimental pela Resolução do CFM n. 1.955, de 2010. Trata-se, assim, de um fenômeno recente, mas a primeira notícia de modificações corporais em 'homem trans' no Brasil data de 1977 (João NERY, 1984).

${ }^{4}$ Conforme Carole Vance (1995, p. 10), várias correntes na Sociologia - interacionismo ocial, estudos do trabalho, história das mulheres e história marxista - e na antropologia imbólica - análises transculturais sobre a sexualidade e estudos do gênero, para mencionar penas as correntes mais significativas que contribuíram para a construção de um enfoque construcionista da sexualidade nas ciências sociais - também servem de base a este trabalho.

${ }^{5}$ Regina FACCHINI, 2009, p. 147.

${ }^{6}$ Laura MOUTINHO, 2004, p. 191.

514 Estudos Feministas, Florianópolis, 20(2): 51 3-523, maio-agosto/2012 
trabalho/lazer. A perspectiva interseccional proposta pelas autoras permite o abandono do raciocínio aritmético simples e mecanicista, que faz equivaler a maior vulnerabilidade à simples soma dos marcadores sociais, sem problematizar sua interferência na particularidade dos contextos estudados.

Dessa forma, não se objetiva aqui a apropriação da categoria social "homem trans" de forma essencializadora e num formato único comum a todos os indivíduos que nela se inscrevam, mas em alguns traços gerais.

\title{
A quem nomeio 'homem trans'
}

Não existe a possibilidade de dizer em termos universais o que é transexualidade tanto a feminina quanto a masculina - nos moldes das concepções que os discursos médicos ajudaram a forjar, daí o recurso a Berenice Bento, para quem tal experiência é

\begin{abstract}
identitária, caracterizada pelo conflito com as normas de gênero. Essa definição confronta-se à aceita pela medicina e pelas ciências psi que a qualificam como uma 'doença mental' e a relaciona ao campo da sexualidade e não ao gênero. Definir a pessoa transexual como doente é aprisioná-lo, fixá-lo em uma posição existencial que encontra no próprio indivíduo a fonte explicativa para seus conflitos, perspectiva divergente daqueles que a interpretam como uma experiência identitária.
\end{abstract}

Márcia Áran traz elementos que complementam a definição anterior, problematizando a costumeira associação da condição transexual à condição de cirurgiado. Assim, para ela "o conceito de transexualidade é bastante problemático do ponto de vista teórico e até científico. E sabemos que a construção do gênero ou os processos identificatórios são muito mais complexos do que a cirurgia". ${ }^{8}$

Assim, é possível falar de pessoas que, em diferentes contextos sociais e culturais, conflituam com o gênero (com que foram assignadas ao nascer e que foi reiterado em grande parte da socialização delas) e, em alguma medida (que não precisa ser cirúrgica/ química), decidem modificá-lo. É possível afirmar que essas pessoas (quase que universalmente) enfrentam dificuldades em função da predominância do binarismo de gênero e da matriz heterossexual na maioria das culturas. Mas a natureza das dificuldades enfrentadas e os dispositivos de enfrentamento não são universais. ${ }^{9}$

Tenho registros etnográficos de alguns sujeitos que não foram incluídos neste artigo como 'homens trans', pois não se definem assim, mas julgo conveniente descrevê-los como forma de delinear melhor a quem nomeio 'homens trans'.

A descrição de 'grupos' segue o único propósito de organizar a escrita e apresentar alguns matizes da complexa 'aquarela das masculinidades' que caracteriza os indivíduos com corpos que foram inicialmente assignados como 'femininos', mas que em alguma medida (variável) se opõem a essa assignação. Não tenho nenhuma pretensão de fixá-los nos quatro grupos que a seguir descrevo, mas tenho uma hipótese de que há transitividade entre esses grupos.

O primeiro grupo é formado por pessoas que não querem um total descolamento do feminino. Permanecem como 'mulheres' por diferentes e variados condicionantes: familiares,

\footnotetext{
${ }^{7}$ Berenice BENTO, 2006, p. 15.

${ }^{8}$ Márcia ÁRAN, 2010, p. 276-277.

${ }^{9}$ Nesse sentido, o enfoque construtivista também é valioso ao explorar a ação e a criatividade humanas em relação à sexualidade, afastando-se dos modelos unidirecionais da mudança social para descrever relacionamentos complexos e dinâmicos entre o Estado, os especialistas profissionais e as subculturas sexuais (VANCE, 1995, p. 16).
} 
subjetivos (medos, incertezas, ceticismo), objetivos e sociais (riscos físicos das modificações corporais, trabalho, sustentação econômica). Isso não as impede de, na intimidade, utilizarem nomes ou apelidos masculinos, alguns objetos característicos da indumentária masculina (como cuecas, camisas, acessórios de cabeça, relógios e sapatos) e, simultaneamente, de conciliá-los com cabelos longos e outros signos sociais que permitem preservá-las (quando desejado ou necessário) na identidade feminina. São mais frequentes em lugares de socialização lésbica de camadas médias.

O segundo grupo é formado por 'homens' que não optam por modificações corporais cirúrgicas nem hormonais. Fazem uso de outros recursos culturais disponíveis para terem a aparência próxima do gênero com o qual mais se afinam (roupas, calçados e cortes de cabelo masculinos, uso de apelido masculino, atividades de trabalho masculinas) e se declaram satisfeitos e efetivamente pertencentes ao gênero masculino. ${ }^{10}$ Trabalham em feiras livres, como camelôs, "papagaios"11 no transporte alternativo informal e em bares populares de socialização lésbica.

Há um terceiro grupo de pessoas que constroem performances públicas ${ }^{12}$ em que os gêneros se misturam, expressando, dessa forma, insatisfação com o 'binarismo dos gêneros' e/ou com a 'heteronormatividade'. Eles/as explicitam o desejo de modificações corporais às vezes pela via, inclusive, da ingestão de testosterona, mas não querem a mastectomia ou outros procedimentos cirúrgicos. São influenciados/as pela 'ideologia igualitarista', cujo espraiamento entre as camadas médias de perfil moderno foi descrito por Maria Luiza Heilborn ${ }^{13} e$, também, por perspectivas de 'desnaturalização das identidades', como as de Judith Butler ${ }^{14}$ e Beatriz Preciado, ${ }^{15}$ entre outras.

Identifiquei ainda um quarto grupo de indivíduos que fazem e/ou desejam modificações corporais através da hormonização por testosterona e de uma ou mais intervenções cirúrgicas, além de se valerem em larga medida de outros recursos sociais (roupas e calçados masculinos, faixas torácicas - a fim de dissimular o volume dos seios e próteses penianas de uso público). Buscam também frequentemente o reconhecimento jurídico do sexo e do nome masculinos e têm se tornado mais visíveis na cena pública brasileira, em função do processo transexualizador no Sistema Único de Saúde (SUS), que favorece o acesso a modificações corporais de alta complexidade. Tais indivíduos já se expressavam de forma diferenciada antes da existência do processo transexualizador, distinguindo-se de maneira mais ou menos sutil da identidade lésbica. A busca do acesso às modificações corporais tem tido o efeito colateral de produzir uma identidade ${ }^{16}$ social radicalmente distinta para além das paredes hospitalares: a de "homem trans".

Na minha percepção tal identidade vem se construindo menos em função do diagnóstico psiquiátrico e mais na suposição de uma completa adesão aos signos corporais e aos comportamentos sociais que constituem as masculinidades, principalmente em seu 'modelo convencional'. Marcos Antonio Ferreira do Nascimento, ao rever os estudos sobre

\footnotetext{
${ }^{10}$ Alguns destes sujeitos podem ser encontrados no documentário Eu sou homem, de Márcia Cabral.

11 "Papagaio" é um termo da gíria carioca para o cobrador de passagens em vans ou combis (normalmente informais). Eventualmente podem ser mulheres, mas não é o padrão.

${ }^{12}$ Estas performances podem incluir roupas e calçados masculinos e femininos, cortes de cabelo andróginos e até uso de dois nomes sociais (um masculino, outro feminino). Quanto à influência da filósofa e ativista espanhola Beatriz Preciado, ver entrevista concedida a Jesús Carrillo, em 2007.

${ }^{13}$ Maria Luiza HEILBORN, 1996, p. 139.

14 Judith BUTLER, 2000.

${ }^{15}$ Beatriz PRECIADO, 2011.

16 Utilizo aqui o conceito de Manuel Castells (1999, p. 23), para quem as identidades "constituem fontes de significado para os próprios atores, por eles originadas, e construídas por meio de um processo de individuação [...]. Identidades organizam significados, enquanto papéis organizam funções".
}

516 Estudos Feministas, Florianópolis, 20(2): 513-523, maio-agosto/2012 
masculinidade, identifica que tal modelo atualmente convive com 'outras maneiras de ser homem', mas que ele ainda pode ser descrito como aquele que preconiza

a ideia de um homem forte, viril, provedor, chefe de família, inserido no mundo público (da 'rua' e do trabalho), competitivo, com pouca conexão com a esfera da vida privada, que tem dificuldades de transitar pelo terreno dos afetos, que não chora e tem um distanciamento das emoções, que não consegue estabelecer vínculos de intimidade, e que pode se comportar de forma agressiva (e até mesmo violenta) contra as mulheres e outros homens.

Utilizo com relação a este último grupo a palavra "transexual" como uma âncora válida para expressar identificação entre sujeitos e algumas experiências sociais em comum, e não para dar corpo a um conjunto de experiências absolutamente idênticas no âmbito das relações de gênero.

\section{'Homens trans': algumas recorrências}

Para realizar uma discussão exploratória ${ }^{18}$ das características que seriam recorrentes entre os 'homens trans', retomo o conceito de transexualidade. Como disse, é uma impossibilidade conceituá-la de forma universal, unívoca e a partir de uma classificação estritamente médico-psiquiátrica.

Os homens trans são diferentes entre si em função dos próprios marcadores sociais de diferenças, como a classe social, a raça/cor, a orientação sexual, a geração, a origem geográfica, entre outras. Eles, de modo geral, utilizam o termo "transexual" ou "trans" frequentemente tomando-o como adjetivo e, por isso, precedido pelo substantivo "homem".

Em suas narrativas, há frequentes experiências de discriminação compostas de marcos, como a rejeição do lugar outorgado pelo binarismo de gênero (baseado na leitura inicial de sua genitália) e por experiências sociais variadas de sexismo e homofobia em decorrência dessa rejeição (ainda na infância e prolongando-se na idade adulta). Essas experiências e marcos culminam na decisão de, em algum momento da vida, reclamar a identidade masculina. Tal decisão é associada não só à possibilidade de obtenção de conforto psíquico, mas de respeito e reconhecimento social.

Pouquíssimas vezes ouvi de homens trans o questionamento do termo "transexual" em função de seu caráter patologizante, ao contrário, usam o termo com frequência e naturalidade. Em seus relatos, há alívio diante do encontro com uma unidade semântica capaz de oferecer inteligibilidade a suas trajetórias pessoais até então inomináveis e, por isso mesmo, mais abjetas. ${ }^{19}$ Eles encontraram o termo após uma deriva em que eram assignados ora como 'lésbicas masculinizadas' (aceitando ou não essa classificação em algum período de suas vidas), com toda a pecha a ela associada, ${ }^{20}$ ora como loucas, ora como ambas.

Reconheço que o termo "transexual" é concretamente cunhado pela classificação médico-psiquiátrica internacional, que reiterou, ao longo de décadas, a ideia de que pessoas trans padecem de um 'transtorno', destituindo-as de parte da autonomia e

17 Marcos Antonio Ferreira do NASCIMENTO, 2011 , p. 45.

${ }^{18}$ Relaciono o sentido exploratório desta discussão ao significado atribuído por Antonio Carlos Gil (2006, p. 43) às pesquisas exploratórias nas ciências sociais em geral, o de desenvolver, esclarecer e modificar conceitos e idéias, tendo em vista a formulação de problemas mais precisos para estudos posteriores". Tratase, portanto, de reflexões inconclusas.

19 Faço referência aqui à acepção do termo já consagrada por Butler (2000).

${ }^{20}$ Para discutir a pecha associada à lésbica masculinizada, ver Guilherme Silva de ALMEIDA e Maria Luiza HEILBORN, 2009, p. 236-341. 
autorizando discursos e condutas variadas dos profissionais de saúde, que vão desde as 'boas práticas'21 às práticas meramente prescritivas, autoritárias e desrespeitosas.

Nesse sentido, ser incluído na categoria trans não implica a desassociação do estigma de 'doente mental', por isso é fundamental não perder de vista a definição foucaultiana do corpo como uma realidade biopolítica, assim como da medicina sempre como uma estratégia biopolítica. ${ }^{22} \mathrm{O}$ termo "transexual" também contribui para transformar pessoas em estereótipos, em que subjetividade, desejo e contexto sociocultural são desconsiderados.

Para alguns profissionais de saúde, e até operadores do direito, entretanto, a 'despatologização do transexualismo', além de desejável, é uma inevitável tendência histórica. Embora possa parecer que o 'discurso médico' e o jurídico assumam sempre feições monolíticas, acríticas e um tanto ingênuas, oculta-se aí a pluralidade de sujeitos, com variadas formações, variável capacidade de crítica e diferentes interesses.

O discurso médico não é único e não é o único a disputar o investimento de significados a termos como transexualidade, ${ }^{23} \mathrm{e}$, a exemplo do que ocorreu com o próprio termo "homossexualidade", ${ }^{24}$ penso que, entre alguns homens com os quais dialogo, há uma reabilitação semântica do termo "transexualidade", apreendido como descritor de vivências singulares, e não como uma patologia.

Alguns homens trans de fato rejeitam o termo "transexual" porque veem a transexualidade como algo transitório que será superado pelo acesso às tecnologias médicas/cirúrgicas e ao reconhecimento judicial. Para eles, não se trata da negação do termo "transexualismo" ou "transexualidade" por seu caráter patologizante, mas de uma rejeição a serem vistos como distintos dos demais homens.

Para alguns, como já mencionei, a identidade trans é categoria temporária, organizadora da experiência e da trajetória individual e, também, uma ferramenta de acesso a instituições que, de outra forma, cerrariam as portas a eles. Utilizar a identidade como ferramenta de acesso cumpre o papel de possibilitar o que, de fato, eles desejam no futuro: eliminá-la.

\section{Construindo homens: autorreconhecimento, indiferenciação e visibilidade}

Uma primeira dificuldade é, em geral, o autorreconhecimento, porque são frequentes as trajetórias de incorporação à subcultura lésbica/gay (pela via do ingresso no movimento LGBT ou não). Em geral, tal incorporação se dá por ausência de outros espaços sociais nos quais encontrar pares. Dessa forma, as experiências trans permanecem subsumidas em espaços lésbicos, reiteradas tanto pelo pouco acesso às tecnologias de modificação corporal quanto pela lógica binária e naturalista de parte das próprias lésbicas e/ou do movimento LGBT, que reitera o dispositivo discursivo de uma identidade lésbica una, indivisível e definida pelo corpo biológico.

\footnotetext{
${ }^{21}$ Faço alusão ao termo do Guía de buenas prácticas para la atención sanitaria a personas trans en el marco del sistema nacional de salud.

${ }^{22}$ Michel FOUCAULT, 1982, p. 80

${ }^{23}$ Para discutir a complexidade dos termos "travesti" e "transexual", consultar a etnografia de Bruno César BARBOSA, 2010.

${ }^{24}$ Com a caracterização dos homossexuais na medicina do século XIX e da própria omossexualidade como anomalia, buscaram-se formas de terapia/tratamento em certa conivência entre a polícia e a medicina (Peter FRY e Edward MACRAE, 1985, p. 66-67).
} 
O processo de autoidentificação dos homens tem ocorrido por contatos pela internet em comunidades virtuais de pares (blogs, sites, Orkut, Facebook), ambientes hospitalares ligados ao processo transexualizador, ${ }^{25}$ universidades e espaços políticos do movimento LGBT, além de redes pessoais e do contato com matérias jornalísticas e programas de TV.

Há restrições a quem decide produzir conhecimento sobre 'homens trans' no Brasil. A primeira delas é a pouca visibilidade. A maior parte da sociedade não considera a possibilidade de transição do gênero feminino ao masculino e, portanto, ignora a própria condição FTM. Isso ocorre em grande medida em razão do olhar falocêntrico que impregna as representações sobre a experiência masculina. Nesse sentido, é como se os comportamentos e os significados considerados masculinos emanassem necessariamente da presença material original do pênis. Tais representações tornam-se evidentes quando muitas pessoas, na presença de homens trans - especialmente dos que dispõem de corpos peludos e musculosos e não fizeram faloplastia -, manifestam extrema perplexidade, como se esses contrariassem toda a lógica e é comum que em seguida utilizem expressões, tais como "como pode ser tão perfeitinho?".

A segunda restrição a estudos é a sua rápida capacidade de passing ${ }^{26}$ (estreitamente vinculada ao desconhecimento social da condição FTM), mas também relacionada à bem elaborada construção de 'corpos sociais masculinos', que se torna especialmente eficaz após a realização da mastectomia e do uso prolongado de testosterona. Em outras palavras, o uso da testosterona no caso dos homens trans, ao contrário do que ocorre com as mulheres trans, torna-os bastante próximos fisicamente às expectativas sociais de como deve parecer um homem, o que contribui para invisibilizálos. Essa invisibilidade adquirida com frequência a duras penas significa para a maior parte um agradável momento de trégua na estressante e contínua batalha por respeito à identidade/expressão de gênero.

Por esse motivo, não sei se homens trans desejam comunidades reais e muito menos formar grupos políticos, ou se a necessidade de encontrar pares se basta nesses encontros pontuais e/ou virtuais de socialização. ${ }^{27}$ É possível que o desejo predominante seja de fato o de sumir na multidão, o 'direito à indiferença'. Esse é facilitado pelo fato de que o passing, como dito, é obtido com facilidade.

O fato de o público não saber, por um lado, possibilita práticas de camuflagem social que favorecem o conforto e o acesso individual a direitos. Por outro lado, principalmente na visão do ativismo, isso prejudica a luta coletiva, inviabiliza o reclame por direitos e faz com que as mulheres trans se sintam solitárias. Há uma expectativa de que os homens trans integrem as principais estratégias utilizadas pelo movimento LGBT nos últimos anos, descritas por Facchini: a incidência política e a visibilidade massiva. ${ }^{28}$

Não se podem subestimar, contudo, os significados políticos dos debates provocados pela simples existência de pessoas trans, os quais implicam rediscussão de rotinas e

\footnotetext{
${ }^{25}$ As salas de espera dos ambulatórios trans têm se constituído como espaços de troca entre mulheres e homens transexuais. Muito embora muitos sujeitos prefiram o anonimato e o silêncio enquanto esperam as consultas, existem aqueles/as que preferem a conversa, dividindo seus conhecimentos sobre as modificações corporais, sobre o cotidiano institucional e, algumas vezes, podendo exibir a seus 'pares mais novos' resultados dos quais têm muito orgulho.

${ }^{26} \mathrm{Na}$ literatura internacional, o termo passing transgender é utilizado para referir-se a uma capacidade pessoal de ser reconhecido/a como pertencente a um gênero que não era o assignado no sujeito ao nascer Essa capacidade pessoal envolve tanto certa manipulação de alguns cuidados físicos característicos do gênero pretendido quanto atributos de comportamento que sejam culturalmente associados a tal gênero.

${ }^{27}$ Os sites brasileiros mais conhecidos são o FTM Brasil e o Sou transhomem... e daí?

${ }^{28}$ FACCHINI, 2009, p. 139.
} 
protocolos institucionais consolidados, como os de atendimento, conduta profissional, sigilo, privacidade ${ }^{29}$ etc. Elas geram deslocamentos: pessoas que jamais inscreveram as relações de gênero e a sexualidade em seu horizonte reflexivo passam, ao menos temporariamente, a considerá-las e a discutir condutas discriminatórias que reconhecem em si e nos demais, e nos extremos dessa abertura ao diálogo, o modelo de sociedade ambicionado.

Politicamente prejudicial ou não, observo satisfação quando a condição anterior às modificações corporais não é mais percebida e/ou mencionada. A possibilidade de ter uma vida organizada sob padrões hegemônicos tende a ser valorizada principalmente por aqueles que se consideram heterossexuais, ${ }^{30}$ expressando-se em semelhança com o 'modelo convencional' de masculinidade. Apesar disso, a adesão a performances convencionais declina quando cresce o reconhecimento público da condição de homem, mesmo entre os 'heterossexuais'.

Nesse sentido, percebo que 'de tudo fica um pouco': ${ }^{31}$ o processo, ainda que acidentado e, em condições negativas, de socialização no gênero feminino, agrega valores, posicionamentos, habilidades e sentimentos, em alguma medida, em oposição ao 'modelo convencional' de masculinidade e, mais comumente, atribuídos às mulheres: apreço por atividades de cuidado, maior conexão com a esfera da vida privada, maior trânsito pelo terreno dos afetos e menor agressividade.

Os homens trans gozam da prerrogativa de poderem obter o reconhecimento jurídico mais facilmente que as mulheres trans: sem a necessidade da cirurgia genital, precisamente por conta de a ortofaloplastia ainda manter seu caráter experimental. ${ }^{32} \mathrm{O}$ que pode soar como vantagem envolve alguns homens trans numa atmosfera de constante vigilância, por medo de serem fisicamente descobertos, por isso avento a hipótese de que a existência dessa atmosfera converte-se em motivação maior para as cirurgias genitais, em detrimento do próprio desejo subjetivo de realizá-las. Trata-se de medos que muitos vocalizam e que João Nery ${ }^{33}$ sintetizou: "[...] não posso perder a consciência e parar numa enfermaria. Vai ser um escândalo. Tenho moto há 40 anos e estou sempre de prontidão". ${ }^{34}$ Embora tal fantasmagoria possa ser enfrentada subjetivamente pelos homens trans de múltiplas formas (pelo acesso à psicoterapia qualificada, no caso dos que desejarem), para alguns, ela só se desfaz na realização de procedimentos cirúrgicos ou nem assim.

${ }^{29}$ Uma curiosa luta foi travada recentemente por um pequeno grupo de pessoas trans que exerciam a docência de ensino superior e/ou eram pesquisadoras/es e alunas/os de pós-graduação, pelo direito ao exercício de suas funções profissionais, o que era dificultado pela impossibilidade de alterar o nome e o sexo do currículo lattes, principal instrumento de aferição de desempenho e socialização de informações técnicoprofissionais. Mesmo no caso dos que já tinham sentenças judiciais que autorizavam, havia uma impossibilidade de a Plataforma Lattes viabilizar a troca. Foram meses de negociação com o Ministério da Ciência e Tecnologia para que um novo protocolo fosse criado pelo CNPq. A luta foi positiva, porque alguns meses depois o que era exceção tornou-se regra extensiva também a usuários de nome social (sem sentença). Dessa forma, a partir de junho de 2011, o CNPq passou a aceitar solicitações de alteração de nome e sexo feitas à Ouvidoria da Instituição.

${ }^{30}$ Entre os homens que conheci, dois se declararam 'bissexual' e 'gay'. Os demais disseram ser heterossexuais ou deixaram isso subentendido pela enunciação apenas de relacionamentos afetivo-sexuais com mulheres. Entre as mulheres que se constituem como namoradas/companheiras/noivas/esposas (as quatro categorias foram utilizadas), duas se disseram bissexuais e as outras duas, heterossexuais.

${ }^{31}$ Referência ao primeiro verso do poema "Resíduo", de Carlos Drummond de ANDRADE, 1945, cuja força estética inspirou anteriormente o trabalho de Esalba Silveira também sobre transexualidade (2006).

${ }^{32}$ Não se trata das leis, mas de parcela da jurisprudência dos processos judiciais de alteração de nome e sexo para homens trans.

${ }_{33}$ João Nery foi o primeiro homem trans do Brasil a realizar modificações corporais e relatá-las no livro Erro de pessoa (1984). E recentemente lançou seu segundo relato biográfico (NERY, 2010).

${ }^{34} \mathrm{O}$ GLOBO, 2010. 
Barbeiros, professores, enfermeiros, técnicos administrativos, alguns desempregados ou subempregados, dependentes economicamente de terceiros, plurais nas masculinidades encenadas e vividas, plurais nos desafios enfrentados e na forma de enfrentá-los... ainda pagam altos e variados preços por ousar ser homens, sem terem os pés no estribo aparentemente sólido da biologia.

\section{Referências}

ALMEIDA, Guilherme Silva de. "Reflexões iniciais sobre o processo transexualizador no SUS a partir de uma experiência de atendimento". In: ARILHA, Margareth; LAPA, Thaís de Souza; PISANESCHI, Tatiane Crenn. Transexualidade, travestilidade e direito à saúde. São Paulo: Oficina Editorial, 2010.

ALMEIDA, Guilherme Silva de; HEILBORN, Maria Luiza. "Não somos mulheres gays: identidade lésbica na visão de ativistas brasileiras". Gênero: Núcleo Transdisciplinar de Estudos de Gênero-Nuteg, v. 9, n. 1, p. 225-249, jan./jun. 2009.

ANDRADE, Carlos Drummond de. "Resíduo". In: . A rosa do povo. Rio de Janeiro: José Olympio, 1945. p. 71.

ARÁN, Márcia. "A saúde como prática de si: do diagnóstico de transtorno de identidade de gênero às redescrições da experiência da transexualidade". In: ARILHA, Margareth; LAPA, Thaís de Souza; PISANESCHI, Tatiane Crenn. Transexualidade, travestilidade e direito à saúde. São Paulo: Oficina Editorial, 2010.

. Novos direitos e visibilidades para os homens trans no Brasil. Disponível em: <http:/ /www.ufscar.br/cis/2010/1 1/novos-diretos-e-visibilidades-para-os-homens-trans-no-brasil/ >. Acesso em: 3 jul. 2012.

ARILHA, Margareth; LAPA, Thaís de Souza; PISANESCHI, Tatiane Crenn. Transexualidade, travestilidade e direito à saúde. São Paulo: Oficina Editorial, 2010.

ÁVILA, Simone; GROSSI, Miriam Pillar. "Maria, Maria João, João: reflexões sobre a transexperiência masculina". In: FAZENDO GÊNERO 9: DIÁSPORAS, DIVERSIDADE, DESLOCAMENTOS, 23 a 26 de agosto de 2010, Florianópolis. Disponível em: <http://www.fazendogenero.ufsc.br/9/ resources/anais/1278255349_ARQUIVO_Maria,MariaJoao,Joao040721010.pdf > . Acesso em: 13 ago. 2011.

BARBOSA, Bruno César. Nomes e diferenças: uma etnografia dos usos das categorias travesti e transexual. Dissertação (Mestrado em Antropologia Social) - Faculdade de Filosofia, Letras e Ciências Humanas, Programa de Pós-Graduação em Antropologia Social, Universidade de São Paulo, São Paulo, 2010.

BENTO, Berenice. A reinvenção do corpo: sexualidade e gênero na experiência transexual. Rio de Janeiro: Garamond, 2006.

BRASIL. Ministério da Saúde. Portaria n. 1.107, de 19 de agosto de 2008. Disponível em: <http://bvsms.saude.gov.br/bvs/saudelegis/gm/2008/prt1707_18_08_2008.html>. Acesso em: 14 ago. 2011.

Conselho Federal de Medicina. Resolução CFM n.1955, de 2010. Dispõe sobre a cirurgia de transgenitalismo e revoga a Resolução CFM n. 1.652/02. Brasília, 2010.

BUTLER, Judith. "Corpos que pesam: sobre os limites discursivos do sexo". In: LOURO, Guacira Lopes. O corpo educado: pedagogias da sexualidade. 2. ed. Belo Horizonte: Autêntica, 2000. p. 153-172.

CARRILLO, Jesús. "Entrevista com Beatriz Preciado". Cadernos Pagu, Campinas, n. 28, p. 375-405, jun. 2007. Disponível em: <http://www.scielo.br/scielo.php?script=sci_arttext\& pid $=$ S0104-83332007000100016\&lng =en\&nrm=iso > . Acesso em: 16 ago. 2011. 
CARVALHO, Mario Felipe de. Que mulher é essa? Identidade, política e saúde no movimento de travestis e transexuais. 2011. Dissertação (Mestrado em Saúde Coletiva) - Programa de Pós-Graduação em Saúde Coletiva, Universidade do Estado do Rio de Janeiro, Rio de Janeiro, 2011.

CASTELLS, Manuel. A Era da Informação: economia, sociedade e cultura. O poder da identidade. 2. ed. São Paulo: Paz e Terra, 1999. v. 2.

FACCHINI, Regina. "Entre compassos e descompassos: um olhar para o 'campo' e para a 'arena' do movimento LGBT brasileiro". Bagoas: Revista de Estudos Gays, v. 3, n. 4, p. 131 158, jan./jun. 2009.

FOUCAULT, Michel. "O nascimento da medicina social". In: ed. Rio de Janeiro: Graal, 1982. cap. V. p. 79-98.

Microfísica do poder. 27.

FRY, Peter; MACRAE, Edward. O que é homossexualidade. São Paulo: Brasiliense, 1985. (Coleção Primeiros Passos).

GIL, Antonio Carlos. Métodos e técnicas de pesquisa. São Paulo: Atlas, 2006.

HEILBORN, Maria Luiza. "Ser ou estar homossexual: dilemas de construção de identidade social”. In: PARKER, Richard. Sexualidades brasileiras. Rio de Janeiro: Relume-Dumará, 1996. p. 137-141.

MOUTINHO, Laura. "'Raça', sexualidade e saúde: discutindo fronteiras e perspectivas". Physis, v. 2, n. 14, p. 191-196, 2004.

NASCIMENTO, Marcos Antonio Ferreira do. Improváveis relações: produção de sentidos sobre o masculino no contexto de amizade entre homens homo e heterossexuais. Dissertação (Doutorado em Saúde Coletiva) - Instituto de Medicina Social, Programa de Pós-Graduação em Saúde Coletiva, Universidade Estadual do Rio de Janeiro, Rio de Janeiro, 2011.

NERY, João W. Erro de pessoa: Joana ou João? Rio de Janeiro: Record, 1984.

Viagem solitária: memórias de um transexual trinta anos depois. Rio de Janeiro: LeYa, 2010.

O GLOBO. Dois cafés e a conta... com João Nery. 17 out. 2010. Disponível em: <http:// ftmbrasil.blogspot.com/201 1/03/materia-com-joao-w-nery-em-revista-o.html>. Acesso em: 14 ago. 2011.

PRECIADO, Beatriz. "Multidões queer: notas para uma política dos 'anormais'”. Revista Estudos Feministas, v. 19, n. 1, p. 11-20, jan./abr. 2011.

RED POR LA DESPATOLOGIZACIÓN DE LAS IDENTIDADES TRANS DEL ESTADO ESPAÑOL. Guía de buenas prácticas para la atención sanitaria a personas trans en el marco del sistema nacional de salud. Disponível em: <http://stp2012.info/guia/STP-propuestasanidad.pdf $>$. Acesso em: 10 set. 2011.

SILVEIRA, Esalba Maria Carvalho. De tudo fica um pouco: a construção social da identidade do transexual. Tese (Doutorado em Serviço Social) - Faculdade de Serviço Social, Programa de Pós-Graduação em Serviço Social, Pontifícia Universidade Católica do Rio Grande do Sul, Porto Alegre, 2006.

SIMONETTI, Cecília. "Relatório". In: ARILHA, Margareth; LAPA, Thaís de Souza; PISANESCHI, Tatiane Crenn. Transexualidade, travestilidade e direito à saúde. São Paulo: Oficina Editorial, 2010.

VANCE, Carole S. "A antropologia redescobre a sexualidade: um comentário teórico". Physis: Revista de Saúde Coletiva, v. 5, n. 1, p. 7-29, 1995.

'Trans Men': New Colours in the Masculinities Picture?

Abstract: The article discusses in an exploratory form the emergence of a new identity category in Brazil, namely "transmen". This identity is constructed as a differentiation from the lesbian identity and also from gender expressions of other groups that had their bodies assigned as 
female upon birth, but that later refuted this assignment without, however, affirming themselves as "men" on a permanent way. The article claims that the emergence of "transmen" has been made possible by the establishment of the transexualization process in the Public Health Care System. Furthermore, the article discusses the use of the term "transman" and some common characteristics related to those persons. The author critiques their complex processes of selfknowledge and construction of masculinities, as well as their quick capacity for non-differentiation from the stand-point of bodily modifications. Finally, the author discusses the political and subjective consequences of their visibility and non-differentiation.

Key Words: Transsexuality; Transsexual Men; Recognition; Gender. 